\title{
Enhancement of Long-Term Potentiation by a Potent Nitric Oxide-Guanylyl Cyclase Activator, 3-(5-Hydroxymethyl-2-furyl)- 1-benzyl-indazole
}

\author{
WEI-LIN CHIEN, KENG-CHEN LIANG, CHE-MING TENG, SHENG-CHU KUO, FANG-YU LEE, and WEN-MEI FU \\ Pharmacological Institute, College of Medicine (W.-L.C., C-M.T., W.-M.F.) and Department of Psychology (K.-C.L.), National Taiwan University;
} Taipei, Taiwan; Graduate Institute of Pharmaceutical Chemistry, China Medical College, Taichung, Taiwan (S.-C.K., F.-Y.L.)

Received September 30, 2002; accepted February 19, 2002

This article is available online at http://molpharm.aspetjournals.org

\begin{abstract}
Nitric oxide (NO) is known to affect synaptic plasticity in various regions of the brain via the cGMP-cGMP-dependent protein kinase (PKG) pathway. We found that a novel compound 3-(5hydroxymethyl-2-furyl)-1-benzyl-indazole (YC-1), a drug known to modulate the response of soluble guanylyl cyclase to NO, greatly potentiates long-term potentiation (LTP). This compound markedly enhanced the induction of LTP in rat hippocampal and amygdala slices by weak tetanic stimulation. The potentiation of LTP by $\mathrm{YC}-1$ was greatly reduced by $\mathrm{NO}$ synthase inhibitor $N^{\mathrm{G}}$-nitroL-arginine-methylester, guanylyl cyclase inhibitor $1 \mathrm{H}$-[1,2,4]oxadiazolo(4,3-a)-quinoxalin-1-one, and PKG inhibitor (9S, 10R,12R)-2,3,9,10,11,12, hexahydro-10-methoxy-2,9-dimethyl-1-ox0-9.12-epoxy-1H-diindolo[1,2,3-fg:3',2',1'-k/]pyrrolo[3,4-1][1,6]benzodiazocine-10-carboxylic acid methyl ester (KT5823). In addition, mitogen-activated protein kinase kinase inhibitor 2' -amino-3'-methoxyflavone (PD98059) also markedly
\end{abstract}

inhibited LTP potentiating action of YC-1. Intracellular increase of $\mathrm{Ca}^{2+}$ concentration derived from $N$-methyl-D-aspartate and glutamate metabotropic receptors contributes to the potentiating action of $\mathrm{YC}-1$. Concurrent perfusion of $\mathrm{YC}-1$ and $\mathrm{NO}$ donor sodium nitroprusside for a short time period resulted in the induction of LTP by stimuli at a frequency as low as $0.02 \mathrm{~Hz}$. Incubation of unstimulated hippocampal slices with YC-1 plus nitroprusside increased the immunofluorescence of phosphoextracellular signal-regulated kinase (ERK) and phospho-cAMP response element binding protein (CREB). Furthermore, the Western blot shows that the phosphorylation of ERKs 1 and 2 and CREB of unstimulated hippocampal slices was increased by YC-1 plus nitroprusside, which was inhibited by KT5823. The NO-cGMP-PKG-ERK signaling pathway thus plays important role in the potentiation of LTP by YC-1.

Learning and memory are two of the most intensively studied subjects in neuroscience. Various approaches have been used to understand the underlying cellular and molecular mechanisms. Long-term potentiation (LTP) has been identified as a potential synaptic mechanism in several regions of the brain involved in learning and memory (Abel and Lattal, 2001; Schafe et al., 2001). Schaffer collateral inputs to pyramidal neurons in the hippocampus CA1 region exhibit a form of LTP that critically depends on $N$-methyl-D-aspartate (NMDA) receptor-mediated $\mathrm{Ca}^{2+}$ influx into the postsynaptic cell (Tsien et al., 1996). It has been suggested that nitric oxide (NO), generated postsynaptically by $\mathrm{Ca}^{2+}$-calmodulinwan

This work was supported by grants from National Science Council of Tai-

ABBREVIATIONS: LTP, long-term potentiation; NMDA, $N$-methyl-D-aspartate; NO, nitric oxide; NOS, nitric-oxide synthase; sGC, soluble guanylyl cyclase; PKG, cGMP-dependent protein kinase; YC-1, 3-(5-hydroxymethyl-2-furyl)-1-benzyl-indazole; ACSF, artificial cerebrospinal fluid; CREB, cyclic AMP response element-binding protein; fEPSP, field excitatory postsynaptic potential; PBS, phosphate-buffered saline; ERK, extracellular signal-regulated kinase; PMSF, phenylmethylsulfonyl fluoride; L-NAME, $\mathrm{N}^{\mathrm{G}}$-nitro-L-arginine-methylester; ODQ, $1 \mathrm{H}$-[1,2,4]-oxadiazolo(4,3-a)quinoxalin-1-one; KT5823, (9S,10R,12R)-2,3,9,10,11,12, hexahydro-10-methoxy-2,9-dimethyl-1-ox0-9.12-epoxy-1H-diindolo[1,2,3-fg:3',2',1'k]pyrrolo[3,4-I][1,6]benzodiazocine-10-carboxylic acid methyl ester; PD98059, 2'-amino-3'-methoxyflavone; AP-5, 2-amino-5-phosphonopentanoic acid; MCPG, $\alpha$-methyl-4-carboxyphenylglycine. 
vitro, in human platelets, and in smooth muscle cells (Ko et al., 1994; Mulsch et al., 1997; Friebe et al., 1998). In the presence of YC-1, NO produced an enormous stimulation of the sensitivity of the purified enzyme to NO up to several hundredfold (Friebe et al., 1996). We here found that YC-1 enhanced LTP in hippocampal Schaffer collateral-CA1 synapse via NO-cGMP-PKG-dependent pathway. In addition, YC-1 potentiated LTP induction in amygdala as well. These findings suggest a therapeutic potential for YC-1 as a drug for improving learning and memory.

\section{Materials and Methods}

Electrophysiology. Transverse slices of hippocampus $(400 \mu \mathrm{m}$ thick) were prepared from adult (150-250 g, for the induction of LTP) Wistar rats. Slices were immediately placed in ice-cold cutting buffer containing $124 \mathrm{mM} \mathrm{NaCl}, 3 \mathrm{mM} \mathrm{KCl}, 1.0 \mathrm{mM} \mathrm{Na}_{2} \mathrm{HPO}_{4}, 25 \mathrm{mM}$ $\mathrm{NaHCO}_{3}, 0.5 \mathrm{mM} \mathrm{CaCl}_{2}, 5.0 \mathrm{mM} \mathrm{MgSO}$, and $10 \mathrm{mM}$ glucose, saturated with $95 \% \mathrm{O}_{2}$ and $5 \% \mathrm{CO}_{2}$. Slices were then maintained in an interface chamber at room temperature, where they were subfused with ACSF consisting of $124 \mathrm{mM} \mathrm{NaCl}, 4.4 \mathrm{mM} \mathrm{KCl}, 1.0 \mathrm{mM}$ $\mathrm{Na}_{2} \mathrm{HPO}_{4}, 25 \mathrm{mM} \mathrm{NaHCO}_{3}, 2.0 \mathrm{mM} \mathrm{CaCl}, 1.0 \mathrm{mM} \mathrm{MgSO}_{4}$, and 10 $\mathrm{mM}$ glucose, bubbled with $95 \% \quad \mathrm{O}_{2} / 5 \% \mathrm{CO}_{2}$. A bipolar tungstenstimulating electrode was placed in the middle of the stratum radiatum in the CA1 region, and extracellular field potentials were recorded using a glass microelectrode (5-10 $\mathrm{M} \Omega$, filled with $2 \mathrm{M} \mathrm{NaCl}$ solution). The pulse duration was $100 \mu \mathrm{s}$, and test responses were elicited at $0.02 \mathrm{~Hz}$. The perfusion rate of ACSF was 1 to $2 \mathrm{ml} / \mathrm{min}$. To record field potentials in the cortico-amygdala pathway, we placed the stimulating electrode in the external capsule, which contained fibers from the auditory cortex to the lateral amygdala. Bicuculine $(10 \mu \mathrm{M})$ was present in the perfusion solution when the fEPSPs of amygdala were recorded. All drugs were perfused in ACSF.

Immunocytochemistry. Hippocampal slices were prepared and treated with drugs for $15 \mathrm{~min}$. After the treatment, the slices were rapidly immersed in ice-cold $4 \%$ paraformaldehyde in PBS, $\mathrm{pH} 7.4$, and fixed for $60 \mathrm{~min}$. The slices were then washed three times in PBS, permeabilized in $0.3 \%$ Triton X-100 in PBS for 60 min at room temperature, and then washed three times in PBS again. Nonspecific antibody binding was blocked by incubation in $10 \%$ goat serum in PBS for $60 \mathrm{~min}$ at room temperature. The slices were then incubated with primary antibody, rabbit polyclonal anti-phospho-cAMP response element-binding protein (CREB; Upstate Biotechnology, Lake Placid, NY) or mouse anti-phospho-extracellular signal-regulated kinase (ERK; Santa Cruz Biotechnology, Santa Cruz, CA), diluted 1:100 in 10\% bovine serum albumin in PBS at $4^{\circ} \mathrm{C}$ for $36 \mathrm{~h}$. The slices were then washed repetitively in PBS and then incubated in fluorescein isothiocyanate-conjugated goat anti-rabbit (Leinco Technologies, Inc., Ballwin, MO) or goat anti-mouse (Jackson ImmuoResearch Laboratories, Inc., West Grove, PA) antibodies diluted 1:100 in PBS at $4^{\circ} \mathrm{C}$. They were then washed again in PBS. The slices were viewed using a Zeiss Axioskop2 microscope (Zeiss, Welwyn Garden City, UK). The specificity of the immunofluorescence was confirmed by omitting the primary antibody, which resulted in a significant reduction in fluorescence intensity.

Western Blotting Analysis. Floating unstimulated hippocampal slices were incubated with ACSF and bubbled with $95 \% \mathrm{O}_{2} / 5 \% \mathrm{CO}_{2}$. The hippocampal slices were treated with drugs for 15 min. After the drug treatment, the slices were homogenized immediately in ice-cold buffer A (50 mM Tris-HCl, pH 7.4, 1 mM EGTA, 1 mM EDTA, $10 \mu \mathrm{M}$ benzamidine, $1 \mu \mathrm{g} / \mathrm{ml}$ aprotinin, $1 \mu \mathrm{g} / \mathrm{ml}$ leupeptin, $2 \mathrm{mM}$ sodium pyrophosphate, $4 \mathrm{mM} p$-nitrophenylphosphate, and $1 \mathrm{mM}$ sodium orthovanadate) and centrifuged at $14,000 \mathrm{~g}$ at $4^{\circ} \mathrm{C}$ for $30 \mathrm{~min}$. The supernatant was decanted, saved, and used as soluble fraction for the detection of pERK.

For preparation of nuclear extracts, the tissue samples were disrupted with a dounce homogenizer in ice-cold buffer B $(0.25 \mathrm{M}$ sucrose, $100 \mathrm{mM} \mathrm{KCl}, 10 \mathrm{mM} \mathrm{NaCl}, 1 \mathrm{mM}$ EGTA, $5 \mathrm{mM}$ EDTA, 50 $\mathrm{mM} \mathrm{NaF}, 1 \mathrm{mM}$ sodium orthovanadate, $1 \mathrm{mM}$ PMSF, $10 \mu \mathrm{M}$ benzamidine, $10 \mu \mathrm{g} / \mathrm{ml}$ leupeptin, and $10 \mu \mathrm{g} / \mathrm{ml}$ aprotinin, $\mathrm{pH} 7.2$ ) and incubated on ice for $10 \mathrm{~min}$ and then centrifuged at $2,000 \mathrm{~g}$ at $4^{\circ} \mathrm{C}$ for $15 \mathrm{~min}$. The supernatant was thrown away, and the pellet was placed in ice-cold buffer $\mathrm{C}$ (10 $\mathrm{mM}$ HEPES, $1.5 \mathrm{mM} \mathrm{MgCl}_{2}, 10 \mathrm{mM}$ $\mathrm{KCl}, 50 \mathrm{mM} \mathrm{NaF}, 1 \mathrm{mM}$ sodium orthovanadate, $1 \mathrm{mM}$ PMSF, 10 $\mu \mathrm{g} / \mathrm{ml}$ leupeptin, and $10 \mu \mathrm{g} / \mathrm{ml}$ aprotinin, $\mathrm{pH}$ 7.2) on ice for $5 \mathrm{~min}$ and then homogenized carefully $(\sim 10-15$ strokes $)$ and centrifuged at $4,000 \mathrm{~g}$ at $4^{\circ} \mathrm{C}$ for $15 \mathrm{~min}$. The nuclear pellet was resuspended in 30 $\mu l$ of buffer D (10 mM HEPES, $1.5 \mathrm{mM} \mathrm{MgCl}_{2}, 1 \mathrm{mM}$ EDTA, $0.8 \mathrm{M}$ $\mathrm{NaCl}, 25 \%$ glycerol, $50 \mathrm{mM} \mathrm{NaF}, 1 \mathrm{mM}$ sodium orthovanadate, $1 \mathrm{mM}$ PMSF, $10 \mu \mathrm{g} / \mathrm{ml}$ leupeptin, and $10 \mu \mathrm{g} / \mathrm{ml}$ aprotinin, $\mathrm{pH}$ 7.0) and incubated for overnight at $4^{\circ} \mathrm{C}$, followed by centrifugation at $14,000 \mathrm{~g}$ at $4^{\circ} \mathrm{C}$ for $15 \mathrm{~min}$. The resulting supernatant was decanted, saved, and used as nuclear extract.

Equivalent amounts of protein for each sample were resolved by $12 \%$ SDS gel, blotted electrophoretically to Immobilon membranes (Millipore, Bedford, MA), blocked for $1 \mathrm{~h}$ with $4 \%$ BSA in PBS, and then incubated overnight at $4^{\circ} \mathrm{C}$ in PBS with a mouse monoclonal or rabbit polyclonal antibody that selectively recognizes phosphorylated ERK1/2 (1:2000; Santa Cruz Biotechnology) or CREB (1:1000; Upstate Biotechnology). After incubation with the primary antibody, the membrane was washed three times with PBS. The blots were subsequently exposed to a donkey anti-rabbit or sheep anti-mouse IgG peroxidase-linked antibody (1:2000; Amersham Biosciences, Piscataway, $\mathrm{NJ}$ ) for $1 \mathrm{~h}$ at room temperature. The blots were visualized by enhanced chemiluminescence using Kodak X-OMAT LS film (Eastman Kodak, Rochester, NY). The density of the immunoblots was determined by ImageQuant software (Amersham Biosciences). To control for protein loading, the membranes then were stripped with stripping buffer $(100 \mathrm{mM}$ mercaptoethanol and $2 \%$ SDS in 62.5 $\mathrm{mM}$ Tris-HCl, $\mathrm{pH} \mathrm{6.8)} \mathrm{for} 30 \mathrm{~min}$ at $60^{\circ} \mathrm{C}$ and reprobed with rabbit polyclonal antibody raised against ERK (1:2000; Santa Cruz Biotechnology) or CREB (1:1000; Cell Signaling Technology, Beverly, MA). The density of the phosphorylated proteins in the immunoblot was normalized to total kinase levels and then expressed as a percentage of those in controls. All protocols complied with institutional guidelines and were approved by Animal Care Committees of Medical College, National Taiwan University.

\section{Results}

Enhancement of LTP by YC-1. We first examined the effects of YC-1 on the induction of LTP in Schaffer collateralCA1 pathway of rat hippocampal slices. As shown in Fig. 1a, two trains of extracellular stimulation of Schaffer collaterals at $100 \mathrm{~Hz}$ for $1 \mathrm{~s}$ induced LTP in the synaptic inputs to CA1 pyramidal cells. Perfusion of YC-1 $(1.6 \mu \mathrm{M})$ for $6 \mathrm{~min}(3 \mathrm{~min}$ before and $3 \mathrm{~min}$ after tetanus) markedly increased the extent of LTP. The fEPSP slope was $163.4 \pm 7.0 \%$ (S.E.M., $n=$ $6)$ and $330.1 \pm 24.9 \%(n=6)$ of the control baseline $50 \mathrm{~min}$ after tetanization without or with YC-1 treatment, respectively. Addition of YC-1 to the bathing solution 10 min after tetanus did not enhance LTP (Fig. 1b), suggesting that the effect of YC-1 occurred only within a few minutes after tetanization and that YC-1 had no effect after LTP was expressed. The effect of YC-1 on synaptic potential by weak tetanus was also examined. As shown in Fig. 1c, weak tetanization $(50 \mathrm{~Hz}$ for $0.5 \mathrm{~s})$ by itself was ineffective in potentiating the synapse. When the same weak tetanus was applied in the presence of YC-1, significant LTP was reliably induced (The slope of fEPSP was $172.9 \pm 10.7 \%$ of the control at $1 \mathrm{~h}$ after tetanization; $n=7$ ). We further examined the effect of YC-1 on the induction of LTP in amygdala. Orthodromic stimuli were applied to the external capsule, which carries 
axons from the auditory cortex to the amygdala. As shown in Fig. 2, three trains (100 $\mathrm{Hz}$ for $1 \mathrm{~s}$ at 3-min intervals) of stimulation induced a transient potentiation that decayed to baseline within $30 \mathrm{~min}$. However, the same trains of stimulation induced an enduring LTP that lasts stably for at least $1 \mathrm{~h}$ in the presence of YC-1 $(n=5)$.

Mechanism of Action of YC-1. It is known that YC-1 binds to an allosteric site on sGC and sensitizes the enzyme toward its gaseous activators $\mathrm{NO}$ and carbon oxide $(\mathrm{CO})$ by
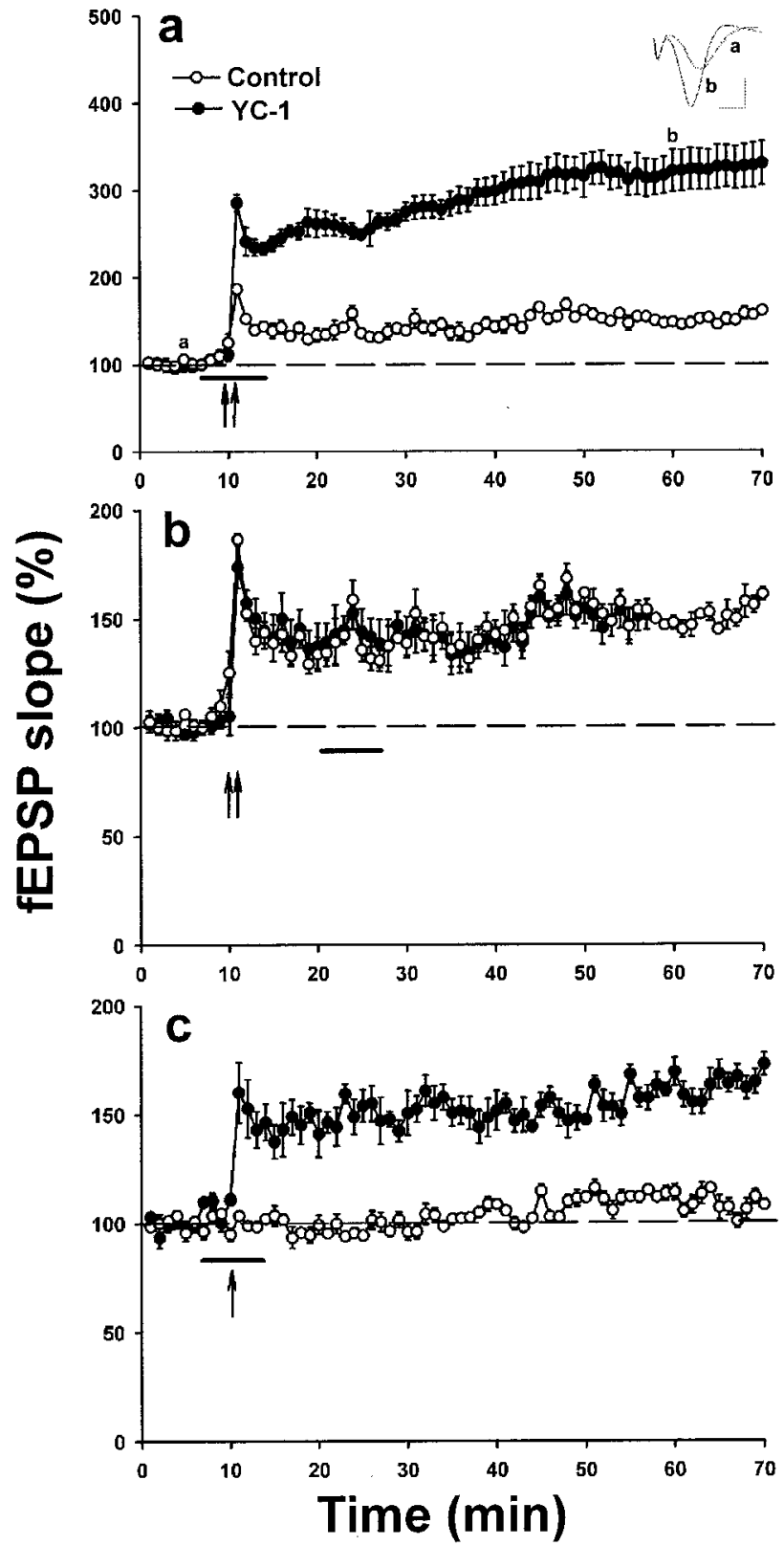

Fig. 1. Enhancement of LTP by YC-1 in hippocampus. Hippocampal slices were stimulated in Schaffer collateral-CA1 pathway at basal stimulating rate at $0.02 \mathrm{~Hz}$. LTP was induced by strong tetanus ( $\mathrm{a}$ and $\mathrm{b}$, twice at $100 \mathrm{~Hz}$ for $1 \mathrm{~s}$ each separated by $20 \mathrm{~s}$ ). Note that compared with control (O), YC-1 (1.6 $\mu \mathrm{M}$; $)$ enhanced LTP when perfused 3 min before and 3 min after tetanus as shown by horizontal bar (a) but not when perfused 10 min after tetanus (b). c, YC-1 $(1.6 \mu \mathrm{M})$ given 3 min before and $3 \mathrm{~min}$ after weak tetanus (once at $50 \mathrm{~Hz}$ for $0.5 \mathrm{~s}$ ) potentiated the induction of LTP. Inset, representative fEPSPs before and 45 min after tetanus in YC-1-treated hippocampal slice are shown. Scale bar: $4 \mathrm{~ms}, 2$ mV. $(n=5 \sim 7$, mean \pm S.E.M. $)$ increasing the maximal catalytic rate (Zabel et al., 1998; Zhao et al., 1998). We thus investigated the role of NO in the mechanism of action of YC-1 on the enhancement of LTP at weak tetanus $(50 \mathrm{~Hz}$ for $0.5 \mathrm{~s}$ ) in hippocampal slices. As shown in Fig. 3a, concomitant administration of YC-1 and NOS inhibitor $N^{\mathrm{G}}$-nitro-L-arginine-methylester (L-NAME,; $300 \mu \mathrm{M}$ ) significantly attenuated the enhancement effect of YC-1. On the other hand, zinc protoporphyrin $(1 \mu \mathrm{M})$, a heme oxygenase inhibitor, did not affect LTP induction by YC-1 (Fig. 3b). Thus, the LTP enhancement of short-term treatment with YC-1 involves processes that are NO- but not CO-dependent.

The principal effector of $\mathrm{NO}$ in many tissues is sGC. Through binding to the heme region of sGC, NO triggers the production of cGMP (Wolin et al., 1982). In view of the finding that $\mathrm{NO}$ enhances LTP in part by activating sGC (Zhuo et al., 1994; Arancio et al., 1995; Son et al., 1998; Lu et al., 1999), we examined the possible involvement of cGMP in the enhancement effect of YC-1 on LTP. Concomitant treatment of YC-1 with $1 \mathrm{H}$-[1,2,4]-oxadiazolo(4,3- $a$ )-quinoxalin-1-one (ODQ; $5 \mu \mathrm{M}$ ), a specific inhibitor of sGC (Garthwaite et al., 1995), completely blocked LTP $(107.8 \pm 3.9 \%, n=5$; Fig. 4a), consistent with the idea that $\mathrm{sGC}$ is involved in both the induction of LTP and the enhancement of LTP by YC-1. The downstream target of cGMP, PKG, is known to contribute to LTP in the hippocampus (Zhuo et al., 1994; Arancio et al., 1995; Son et al., 1998; Lu et al., 1999; Arancio et al., 2001). We therefore examined the effects of a PKG inhibitor, KT5823, on enhancement of LTP by YC-1. As shown in Fig. $4 \mathrm{~b}$, simultaneous perfusion of KT $5823(2 \mu \mathrm{M})$ produced a significant inhibition of LTP induced by YC-1 $(112.5 \pm 6.7 \%$; $n=5$ ). One protein kinase family that has been implicated in the expression of LTP is the ERKs. Concomitant application of ERK kinase inhibitor PD98059 $(10 \mu \mathrm{M})$ with YC-1 also significantly antagonized LTP potentiating action of YC-1 (Fig. 4c). Our results suggest that the NO-cGMP-PKG-ERK signaling pathway is involved in the enhancement of LTP by YC-1.

The activation of NOS is $\mathrm{Ca}^{2+}$-dependent and the influx of

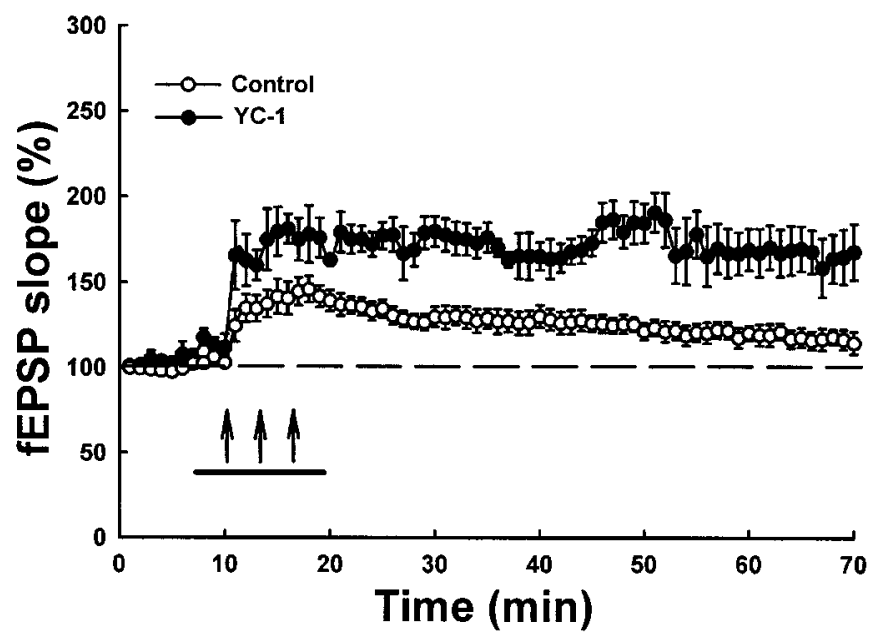

Fig. 2. Enhancement of LTP by YC-1 in amygdala. LTP was induced in lateral amygdala. Orthodromic stimuli were applied to the external capsule, which carries axons from the auditory cortex to the amygdala, and field recordings were made from the lateral amygdala. Strong tetani (100 $\mathrm{Hz}$ for $1 \mathrm{~s}$ at 3-min intervals) were applied as shown by arrow. Note that application of YC-1 $(3.2 \mu \mathrm{M}) 3 \mathrm{~min}$ before and $3 \mathrm{~min}$ after tetanus induced an enduring LTP in amygdala. $(n=4$, mean \pm S.E.M.) 
$\mathrm{Ca}^{2+}$ through NMDA receptor is essential for induction of LTP in the hippocampal Schaffer collateral-CA1 pathway. As shown in Fig. 5a, the presence of 2-amino-5-phosphonopentanoic acid (AP-5; $100 \mu \mathrm{M})$, an antagonist of NMDA receptors, attenuated the amplitude of LTP by YC-1 at weak tetanus stimulation, suggesting that certain consequences brought about by NMDA receptor activation, presumably $\mathrm{Ca}^{2+}$ influx, play a role in the LTP induced by YC-1. Consistent with the involvement of metabotropic receptor in LTP, $\alpha$-methyl-4-carboxyphenylglycine (MCPG; $100 \mu \mathrm{M}$ ) also significantly attenuated the amplitude of LTP by YC-1 (Fig. 5b). Simultaneous application of AP-5 and MCPG markedly an-

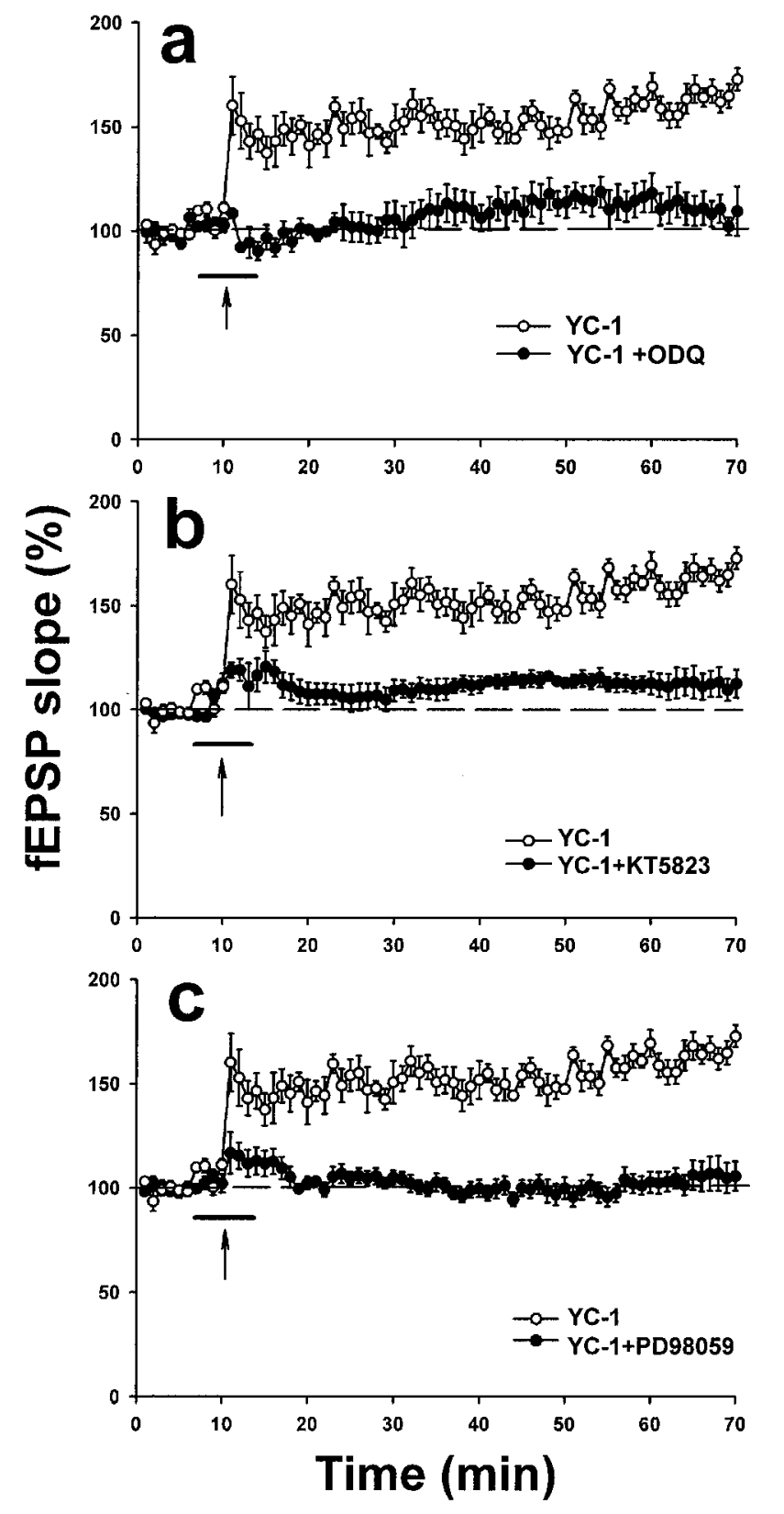

Fig. 3. NO-dependent enhancement of LTP by YC-1. LTP induced by one train of $50 \mathrm{~Hz}$ for $0.5 \mathrm{~s}$ tetanization (arrow) in the presence of YC-1 in hippocampal slice was inhibited by concomitant perfusion of NO synthase inhibitor L-NAME (300 $\mu \mathrm{M}$, a) but not by the heme oxygenase inhibitor zinc protoporphyrin $(1 \mu \mathrm{M}, \mathrm{b})$. Horizontal bar represents the perfusion period of drugs. tagonized LTP induced by YC-1 at weak tetanic stimulation (Fig. $5 \mathrm{~b} ; 112.4 \pm 5.2 \%, \mathrm{n}=5$ ).

Effects of YC-1 on the Synaptic Plasticity in the Presence of NO Donor. NO is released by NOS, which is activated by $\mathrm{Ca}^{2+}$ influx upon high-frequency tetanic stimulation. We therefore investigated the downstream mechanism of YC-1 by the addition of NO donor to hippocampal slices to mimic high frequency stimulation. As shown in Fig. 6, we delivered a basal electrical stimulation at $0.02 \mathrm{~Hz}$ throughout the whole experimental period for the monitoring of the synaptic response in the presence of YC-1 $(1.6 \mu \mathrm{M})$ and NO donor sodium nitroprusside $(300 \mu \mathrm{M})$. It was found that concurrent perfusion of YC-1 with sodium nitroprusside for 6 min re-
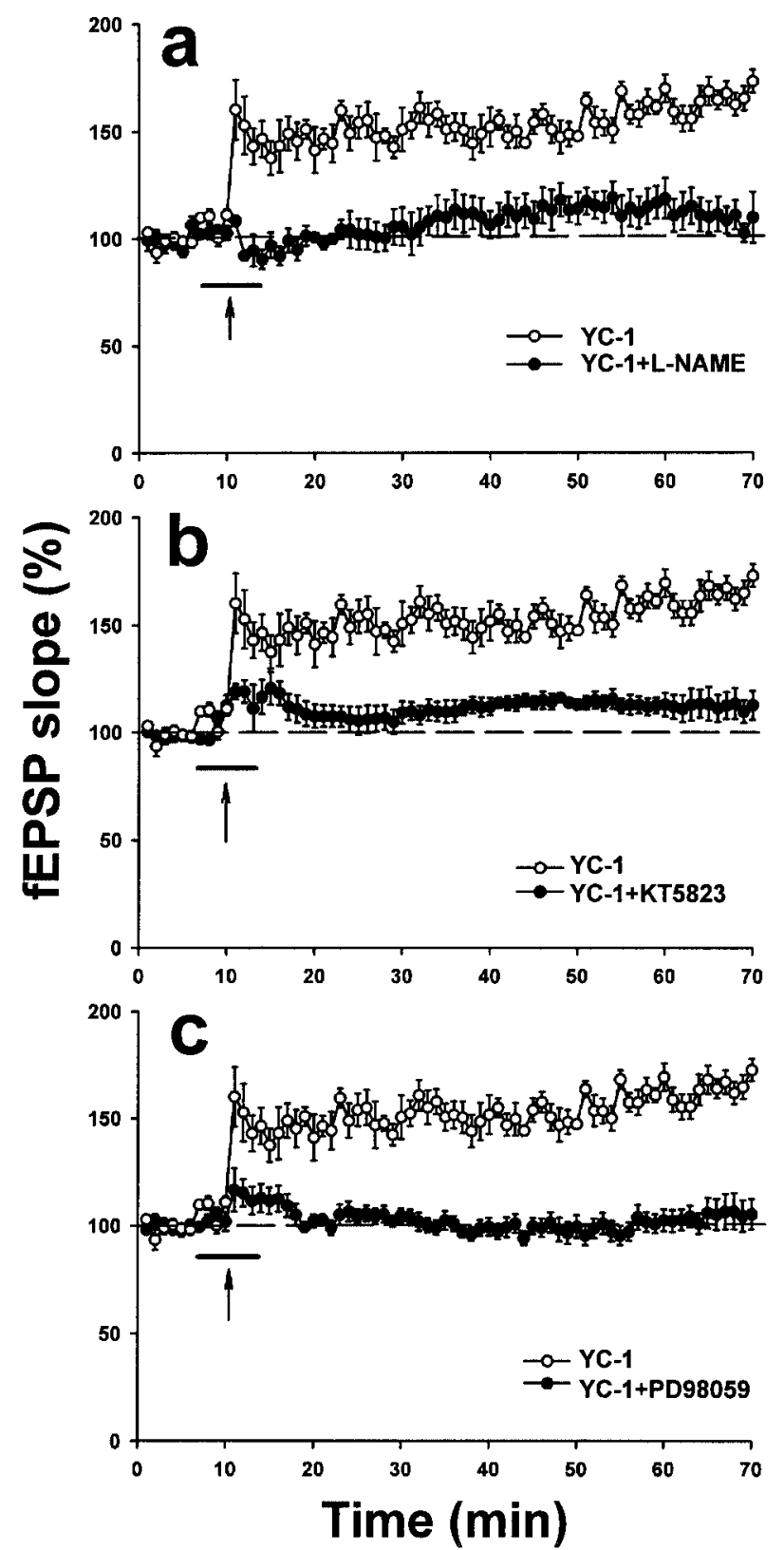

Fig. 4. Guanylyl cylase, PKG, and ERK are involved in the potentiation of LTP by YC-1. LTP induced by one train of $50 \mathrm{~Hz}$ for $0.5 \mathrm{~s}$ tetanization (arrow) in the presence of YC-1 in hippocampal slice was inhibited by concomitant perfusion of the guanylyl cyclase inhibitor ODQ (5 $\mu \mathrm{M}$, a), PKG inhibitor KT5823 (2 $\mu \mathrm{M}, \mathrm{b})$, or ERK kinase inhibitor PD98059 (10 $\mu \mathrm{M}, \mathrm{c})$. Horizontal bar represents the perfusion period of drugs $(n=5 \sim 7)$. 
sulted in the induction of LTP at basal stimulation, indicating that NO donor is able to mimic the action of high frequency tetanic stimulation in the presence of YC-1. YC-1 or sodium nitroprusside alone had no effect on synaptic transmission at stimulating frequency of $0.02 \mathrm{~Hz}$.

It has been reported that the ERK cascade is essential for long-term synaptic plasticity and for certain types of learning (English and Sweatt, 1997; Blum et al., 1999). Furthermore, the transactivation of CREB by ERK plays an essential role in synaptic plasticity and memory formation (Impey et al., 1999). We thus examined the effect of YC-1 on the phosphor-

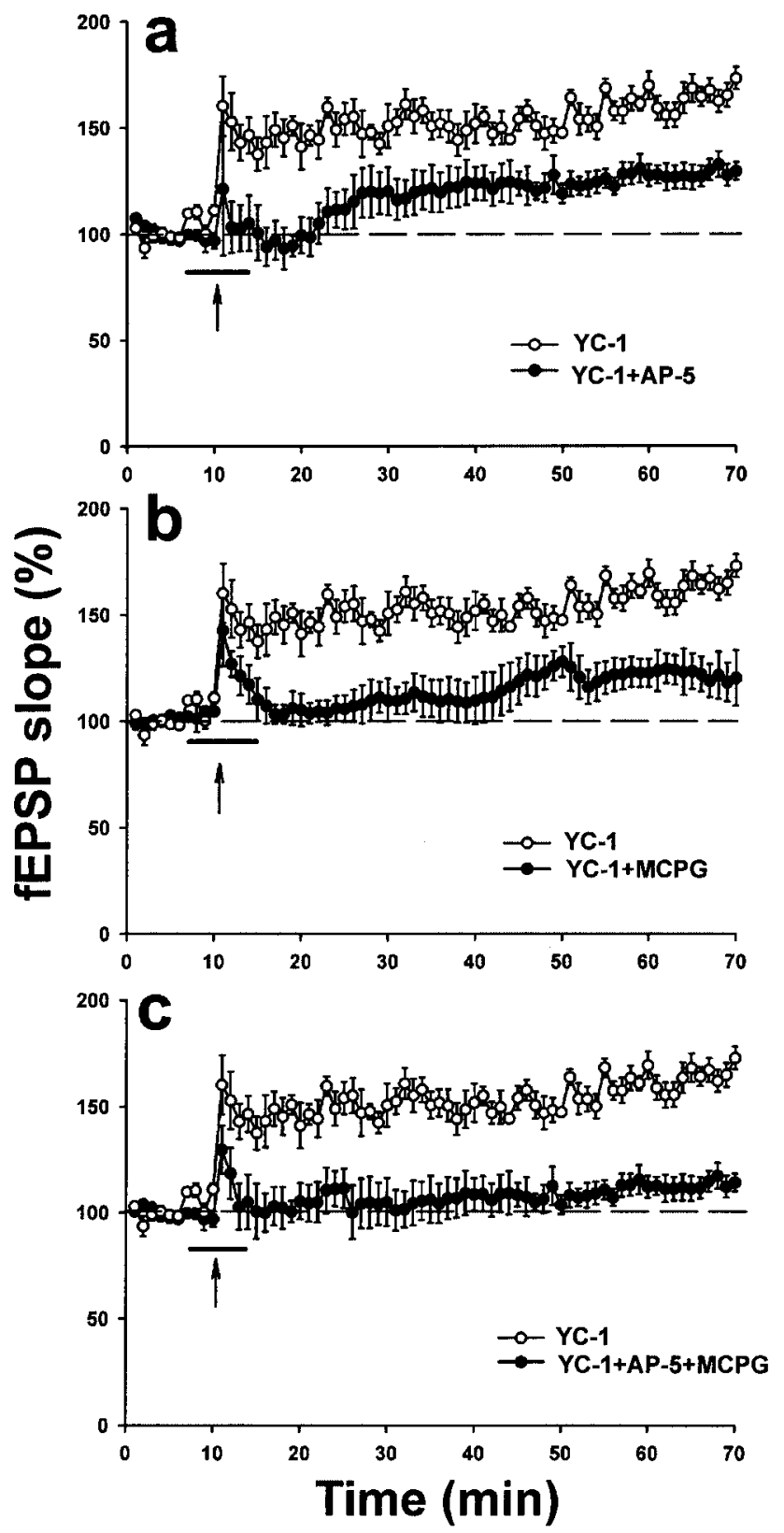

Fig. 5. NMDA and metabotropic glutamate receptors are involved in the enhancement of LTP by YC-1. LTP was induced by one train of $50 \mathrm{~Hz}$ for $0.5 \mathrm{~s}$ tetanization (arrow) in the presence of YC- 1 in hippocampal slice. Application of YC-1 with NMDA receptor antagonist AP-5 (100 $\mu \mathrm{M}$, a) or metabotropic receptor antagonist MCPG (b) inhibited the amplitude of LTP. Simultaneous application of both AP-5 and MCPG abolished the expression of LTP (b). Horizontal bar represents the perfusion period of drugs. ylation of ERK and CREB in the presence of NO donor in unstimulated hippocampal slices. As shown in Fig. 7, little fluorescence was detected in CA1 area of control hippocampal slices. However, incubation of hippocampal slices with YC-1 (1.6 $\mu \mathrm{M})$ and sodium nitroprusside $(300 \mu \mathrm{M})$ for 15 min markedly enhanced the fluorescence of pERK and pCREB. We then used Western blotting analysis to examine the effect of YC-1 on the activation of ERK and CREB. The floating hippocampal slices were treated with YC-1 $(1.6 \mu \mathrm{M})$ and sodium nitroprusside (300 $\mu \mathrm{M})$ for $15 \mathrm{~min}$ and then were used for the detection of pERK and pCREB by Western blot. As shown in Fig. 8a, pERK antibody yielded two bands of 42 and $44 \mathrm{kDa}$ corresponding to ERKs 2 and 1, respectively. Immediately after the application of YC-1 plus nitroprusside for $15 \mathrm{~min}$, we observed a significant increase in pERK 1 and pERK 2 relative to control slices. Densitometric analysis revealed an increase in pERK 1 and pERK 2 (238 \pm 30 and $177 \pm 32 \%$ of control for pERK 1 and pERK 2, respectively; $n=4$ ) (Fig. 8a). The increase of pERK was inhibited by concomitant treatment with PKG inhibitor 2 $\mu \mathrm{M}$ KT5823 (165 \pm 33 and $134 \pm 25 \%$ of control for pERK 1 and pERK 2, respectively; $n=4$ ). Furthermore, CREB phosphorylation of un-stimulated hippocampal slices was also enhanced by the treatment of YC-1 $(1.6 \mu \mathrm{M})$ and sodium nitroprusside $(300 \mu \mathrm{M})$, which was also antagonized by PKG inhibitor KT5823 $(2 \mu \mathrm{M})$ (Fig. 8b). These results indicate that ERKCREB activation may be the downstream target of PKG in response to the action of $\mathrm{YC}-1$.

\section{Discussion}

Nitric-oxide synthase is widespread in the nervous system and NO is thought to play important roles in activity-dependent synaptic plasticity as well as a variety of forms of learning and memory (Watanabe et al., 1995; Hawkins et al., 1996; Teledgy and Kokavszky, 1997; Prast and Philippu, 2001). In general, the relation between synaptic plasticity and various forms of learning has been investigated by inhibiting synaptic plasticity in a living animal and examine the consequences on later retention behavior. In the present study, we

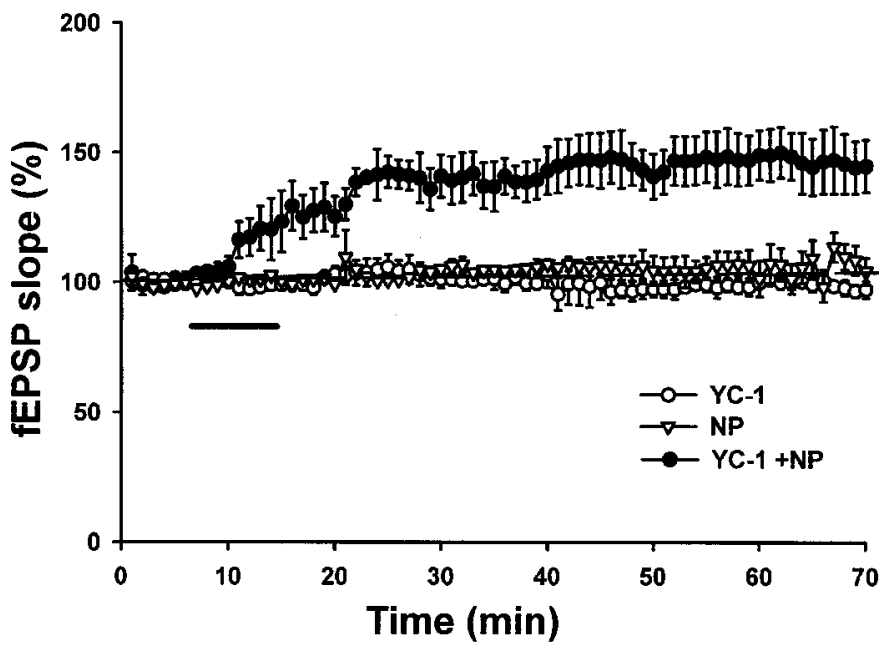

Fig. 6. Effect of YC-1 on the synaptic plasticity in the presence of NO donor. Hippocampal slices were stimulated in Schaffer collateral-CA1 pathway at basal stimulating rate at $0.02 \mathrm{~Hz}$. Note that simultaneous perfusion of YC-1 $(1.6 \mu \mathrm{M})$ and nitroprusside $(\mathrm{NP}, 300 \mu \mathrm{M})$ for $6 \mathrm{~min}$ caused the induction of LTP at a stimulating frequency as low as $0.02 \mathrm{~Hz}$. YC-1 or nitroprusside alone produced no enhancement. 
pERK
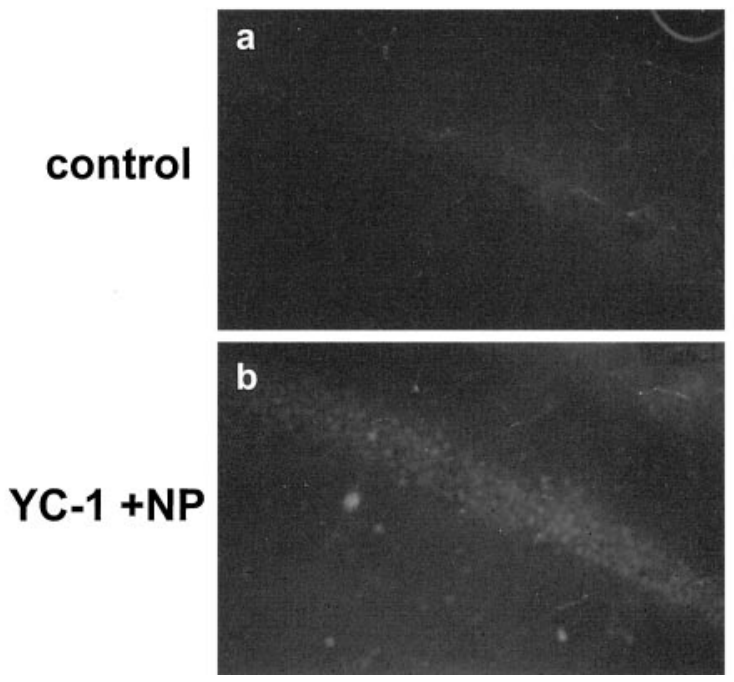

PCREB
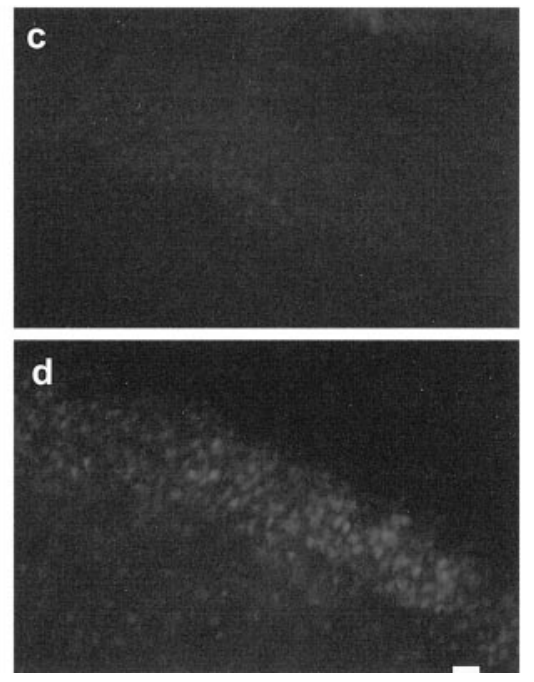

Fig. 7. Increase of immunofluorescence of pERK and pCREB by YC-1 in the presence of NO donor. The floating un-stimulated hippocampal slices were treated with YC-1 $(1.6 \mu \mathrm{M})$ plus sodium nitroprusside (NP, $300 \mu \mathrm{M}$ ) for $15 \mathrm{~min}$ in the presence of $95 \% \mathrm{O}_{2}$ and $5 \% \mathrm{CO}_{2}$ at $31^{\circ} \mathrm{C}$. The slices were then fixed for the immunofluorescent labeling. Note that compared with control $(\mathrm{a}, \mathrm{c})$ treatment with YC-1 plus sodium nitroprusside (b, d) markedly enhanced the immunofluorescence of both pERK and pCREB. Scale bar, $50 \mu \mathrm{m}(\mathrm{a}, \mathrm{b})$ and $100 \mu \mathrm{m}(\mathrm{c}, \mathrm{d})$. have demonstrated that YC-1 enhances synaptic plasticity of hippocampus through a NO-dependent pathway.

The novel compound YC-1 turns $\mathrm{CO}$ and NO into potent activators of sGC, leading to an increase of $\sim 100$ - to 1000 -fold in enzyme activity (Friebe et al., 1996). Binding of YC-1 to an allosteric site on sGC sensitizes the enzyme toward its gaseous activators by reducing the ligand dissociation rate from the heme group (Friebe et al., 1998). To investigate a possible role for $\mathrm{CO}$ in the enhancement of LTP by YC-1, we have blocked the production of $\mathrm{CO}$ in hippocampal slices. Heme oxygenase inhibitor zinc protoporphyrin-IX did not affect LTP induced by weak tetanus paired with $\mathrm{YC}-1$ administration, suggesting that $\mathrm{CO}$ may not be involved in the LTP potentiation of YC-1.

The involvement of NO in the action of $\mathrm{YC}-1$ was indicated by the finding that LTP induction by weak tetanus paired
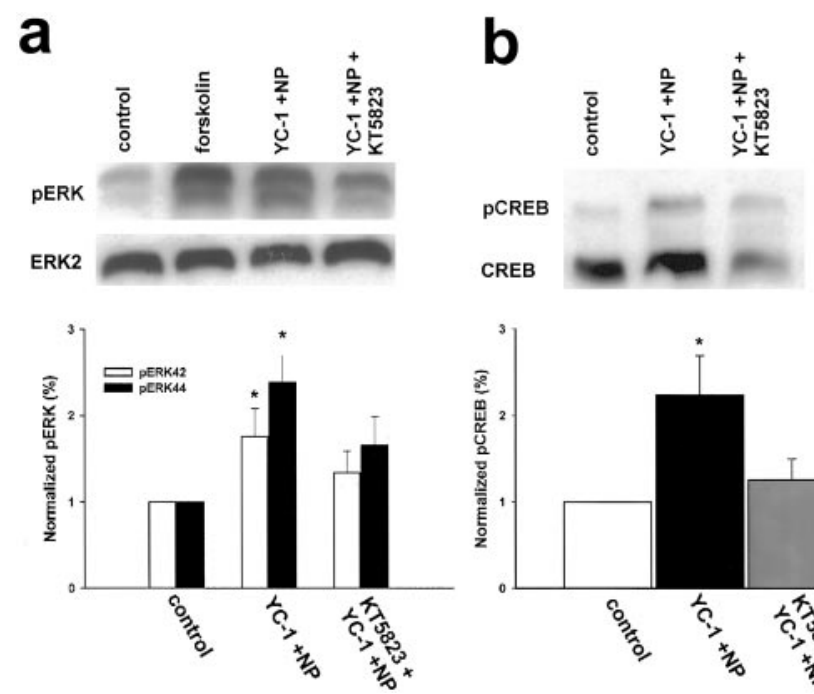

Fig. 8. Increase of phosphorylation of ERK and CREB by YC-1 using Western blotting analysis. The floating unstimulated hippocampal slices were treated with various drugs for $15 \mathrm{~min}$ in the presence of $95 \% \mathrm{O}_{2} / 5 \%$ $\mathrm{CO}_{2}$ at $31^{\circ} \mathrm{C}$. The cytosolic and nuclear proteins were then collected by lysis buffer for the Western blotting analysis of pERK and pCREB. Note that YC-1 (1.6 $\mu \mathrm{M})$ plus sodium nitroprusside (NP, $300 \mu \mathrm{M})$ increased the phosphorylation of both ERK (a) and CREB (b), which was inhibited by 2 $\mu \mathrm{M}$ KT5823. The summarized results were shown in the lower panels $(n=3 \sim 4)$. ${ }^{*}, p<0.05$ compared with control using Student's $t$ test. with the YC-1 treatment was markedly inhibited by NOS inhibitor L-NAME. Moreover, LTP can be induced by weak stimulation even at a frequency as low as $0.02 \mathrm{~Hz}$ when paired with the NO donor sodium nitroprusside in the presence of YC-1. Both GC inhibitor ODQ and PKG inhibitor KT5823 inhibited the enhancement of LTP by YC-1, suggesting that the NO-cGMP-PKG pathway mediated the influence of YC-1 on synaptic plasticity. It has been demonstrated that NO may be particularly important in regulating the threshold of LTP induction, because NOS inhibitors blocked LTP induced by weak, but not strong, afferent stimulation in CA1 (O'Dell et al., 1994; Malen and Chapman, 1997; Zhuo et al., 1998; Lu et al., 1999). Here we showed that YC-1 induced LTP at weak tetanus by amplifying the signal transduction of NO, indicating that YC-1 also lowers the threshold for LTP induction.

We found that weak tetanic stimulation at $50 \mathrm{~Hz}$ for $0.5 \mathrm{~s}$ did not induce LTP unless YC-1 was present. The role of $\mathrm{Ca}^{2+}$ release from intracellular stores has been implicated in hippocampal CA1 plasticity (Wang et al., 1996). Treatment of either AP5 or MCPG alone attenuated the enhancement of LTP by YC-1. However, simultaneous treatment of both antagonists abolished the action of YC-1 on LTP. These results suggest that $\mathrm{Ca}^{2+}$ influx from NMDA receptor and inositol trisphosphateinduced $\mathrm{Ca}^{2+}$ release through metabotropic glutamate receptors all contribute to the enhancement of LTP by YC-1. Increase of cytosolic $\mathrm{Ca}^{2+}$ is thus necessary for the activation of NOS to produce NO and for the full expression of the action of YC-1. Our findings that YC-1 did not enhance LTP when applied 10 min after weak tetanus $(50 \mathrm{~Hz}$ for $0.5 \mathrm{~s}$ ) is consistent with the short-lifetime of NO released by weak tetanus, the NO-dependent action of YC-1, and also the finding that PKG activator does not cause LTP when applied 5 min after weak tetanus (50 $\mathrm{Hz}$ for $0.5 \mathrm{~s}$ ) in the CA1 region of guinea pig hippocampal slices (Zhuo et al., 1994). NO diffusion is spatially restricted and NO production requires a minimum level of synaptic activity, which limits the synapses modified by NO to the activated pathway only (Hawkins et al., 1993). This property of NO allows YC-1 to enhance LTP in an input-specific manner; hence, its influence on behavior is experience-dependent. Nitric oxide induces cyto- 
solic production of cGMP, which modulates synaptic functions, leading to the early phase of LTP (Hawkins et al., 1998).

There is abundant cross-talk between kinase pathways, suggesting that ERK may be a point of convergence integrating signals of protein kinase $\mathrm{C}$, protein kinase $\mathrm{A}$, and $\mathrm{Ca}^{2+}$. calmodulin-dependent protein kinase (Roberson et al., 1999; Vanhoutte et al., 1999), in addition to the activity of individual signaling systems. The NO-cGMP-PKG pathway may also contribute to the late phase of LTP by causing induction of immediate early genes through phosphorylation of CREB (Gudi et al., 1996). CREB phosphorylation and gene induction are thought to contribute to the late, protein synthesisdependent phase of hippocampal LTP (Bourtchouladze et al., 1994; Carew and Sutton, 2001), which may involve presynaptic as well as postsynaptic changes (Lu et al., 1999). Inhibition of ERK phosphorylation and nuclear translocation prevents CREB phosphorylation and results in rapidly decaying LTP (Davis et al., 2000). Our study shows that ERK and its downstream transcription factor CREB are rapidly phosphorylated after treatment of $\mathrm{YC}-1$ in the presence of $\mathrm{NO}$ donor. The phosphorylation of both ERK and CREB by YC-1 plus NO donor was inhibited by PKG inhibitor KT5823, suggesting that PKG-ERK-CREB pathways are involved in the LTP potentiating action of YC-1. The relation between LTP and memory is a focus of intensive investigation (Malenka and Nicoll, 1999). Nitric-oxide synthase inhibitors reduce the capability of treated animals to acquire or retain information in several learning tasks (Prast and Philippu, 2001). Our preliminary results show that administration of YC-1 greatly improved learning and memory in several tasks involving different brain regions (data not shown).

In conclusion, the results of the present study show that YC-1 enhances LTP in both hippocampal and amygdala slices. The remarkable characteristics of $\mathrm{YC}-1$ in potentiating NO-stimulated GC activity during the induction of activity-dependent synaptic plasticity and the high spatial and temporal specificity of NO-induced cellular actions warrant that YC-1 will enhance acquisition of new information without affecting previously consolidated memory and suggest that NO-GC activators may be good candidates for new therapeutic drugs aiming at improving learning and memory in humans.

\section{Acknowledgments}

We appreciate the help of Professor Poo M. M. (University of California at Berkeley) for the polishing of the manuscript.

\section{References}

Abel T and Lattal KM (2001) Molecular mechanisms of memory acquisition, consolidation and retrieval. Curr Opin Neurobiol 11:180-187.

Arancio O, Antonova I, Gambaryan S, Lohmann SM, Wood JS, Lawrence DS, and Hawkins RD (2001) Presynaptic role of cGMP-dependent protein kinase during long-lasting potentiation. J Neurosci 21:143-149.

Arancio O, Kandel ER, and Hawkins RD (1995) Activity-dependent long-term en hancement of transmitter release by presynaptic $3^{\prime}, 5^{\prime}$-cyclic GMP in cultured hippocampal neurons. Nature (Lond) 376:74-80.

Blum S, Morre AN, Adams F, and Dash PA (1999) Mitogen-activated protein kinase cascade in the CA1/CA2 subfield of the dorsal hippocampus is essential for longterm spatial memory. J Neurosci 19:3535-3544.

Bourtchouladze R, Frenguelli B, Blendy J, Cioffi D, Schutz G, and Silva AJ (1994) Deficient long-term memory in mice with a targeted mutation of the cAMPresponsive element-binding protein. Cell 79:59-68.

Carew TJ and Sutton MA (2001) Molecular stepping stones in memory consolidation. Nature Neurosci 4:769-771.

Davis S, Vanhoutte P, Pages C, Caboche J, and Laroche S (2000) The MAPK/ERK cascade targets both Elk-1 and cAMP response element-binding protein to control long-term potentiation-dependent gene expression in the dentate gyrus in vivo $J$ Neurosci 20:4563-4572.

English JD and Sweatt JD (1997) Requirement for the mitogen-activated protein kinase cascade in hippocampal long-term potentiation. J Biol Chem 272:1910319106.

Friebe A, Mullershausen F, Smolenski A, Walter U, Schultz G, and Koesling D (1998) YC-1 potentiates nitric oxide- and carbon monoxide-induced cyclic GMP effects in human platelets. Mol Pharmacol 54:962-967.

Friebe A, Schultz G, and Koesling D (1996) Sensitizing soluble guanylyl cyclase to become a highly CO-sensitive enzyme. EMBO (Eur Mol Biol Organ) J 15:68636868.

Garthwaite J, Southam E, Boulton CL, Nielson EB, Schmidt K, and Mayer B (1995) Potent and selective inhibition of nitric oxide sensitive guanylyl cyclase by $1 \mathrm{H}$ $[1,2,4]$ oxadiazolo $[4,3 \alpha]$ quinoxalin-1-one. Mol Pharmacol 48:184-188.

Gudi T, Huvar I, Meinecke M, Lohmann SM, Boss GR, and Pilz RB (1996) Regulation of gene expression by cGMP-dependent protein kinase. J Biol Chem 271:45974600

Haley JE, Wilcox GL, and Chapman PF (1992) The role of nitric oxide in hippocampal long-term potentiation. Neuron 8:211-216.

Hawkins RD (1996) NO honey, I don't remember. Neuron 16:465-467.

Hawkins RD, Kandel ER, and Siegelbaum SA (1993) Learning to modulate transmitter release: themes and variations in synaptic plasticity. Annu Rev Neurosci 16:625-665.

Hawkins RD, Son H, and Arancio O (1998) Nitric oxide as a retrograde messenger during long-term potentiation in hippocampus. Prog Brain Res 118:155-172.

Ko FN, Wu CC, Kuo SC, Lee FY, and Teng CM (1994) YC-1, a novel activator of platelet guanylate cyclase. Blood 84:4226-4233.

Impey S, Obrietan K, and Storm DR (1999) Making new connections: role of ERK MAP kinase signaling in neuronal plasticity. Neuron 23:11-14

Lu YF, Kandel ER, and Hawkins RD (1999) Nitric oxide signaling contributes to late-phase LTP and CREB phosphorylation in the hippocampus. $J$ Neurosci 19: 10250-10261.

Malen PL and Chapman PF (1997) Nitric oxide facilitates long-term potentiation, but not long-term depression. J Neurosci 17:2645-2651.

Malenka RC and Nicoll RA (1999) Long-term potentiation-a decade of progress? Science (Wash DC) 285:1870-1874.

Mulsch A, Bauersachs J, Schafer A, Stasch JP, Kast R, and Busse R (1997) Effect of YC-1, an NO-independent, superoxide-sensitive stimulator of soluble guanyly cyclase, on smooth muscle responsiveness to nitrovasodilators. $\mathrm{Br} J$ Pharmaco 120:681-689.

O'Dell TJ, Huang PL, Danwson TM, Dinerman JL, Snyder SH, Kandel ER, and Fishman MC (1994) Endothelial NOS and the blockade of LTP by NOS inhibitors in mice lacking neuronal NOS. Science (Wash DC) 265:542-546.

Prast $\mathrm{H}$ and Philippu A (2001) Nitric oxide as modulator of neuronal function. Prog Neurobiol 64:51-68.

Roberson ED, English JD, Adams JP, Selcher JC, Kondratick S, and Sweatt JD (1999) The mitogen-activated protein kinase cascade couples PKA and PKC to cAMP response element binding protein phosphorylation in area CA1 of the hippocampus. J Neurosci 19:4337-4348.

Schafe GE, Nader K, Blair HT, and LeDoux JE (2001) Memory consolidation of Pavlovian fear conditioning: a cellular and molecular perspective. Trends Neurosci 24:540-546.

Son H, Hawkins RD, Martin K, Kiebler M, Huang PL, Fishman MC, and Kandel ER (1996) Long-term potentiation is reduced in mice that are doubly mutant in endothelial and neuronal nitric oxide synthase. Cell 87:1015-1023.

Son H, Lu YF, Zhuo M, Arancio O, Kandel ER, and Hawkins RD (1998) The specific role of cGMP in hippocampal LTP. Learn Mem 5:231-245.

Teledgy G and Kokavszky R (1997) The role of nitric oxide in passive avoidance learning. Neuropharmacology 36:1583-1587.

Tsien JZ, Huerta PT, and Tonegawa S (1996) The essential role of hippocampal CA1 NMDA receptor-dependent synaptic plasticity in spatial learning. Cell 87:13271338.

Vanhoutte P, Barnier JV, Guibert B, Pages C, Besson MJ, Hipskind RA, and Caboche J (1999) Glutamate induces phosphorylation of Elk-1 and CREB, along with c-fos activation via an extracellular signal-regulated kinase-dependent pathway in brain slices. Mol Cell Biol 19:136-146.

Wang Y, Wu J, Rowan MJ, and Anwyl R (1996) Ryanodine produces a low frequency stimulation-induced NMDA receptor-independent long-term potentiation in the rat dentate gyrus in vitro. J Physiol (Lond) 495:755-767.

Watanabe Y, Saito H, and Abe K (1995) Nitric oxide is involved in long-term potentiation in the medial but not lateral amygdala neuron synapses in vitro. Brain Res 688:233-236.

Wilson RI, Yanovsky J, Godecke A, Stevens DR, Schrader J, and Haas HL (1997) Endothelial nitric oxide synthase and LTP. Nature (Lond) 386:338.

Wolin MS, Wood KS, and Ignarro LJ (1982) Guanylate cyclase from bovine lung. A kinetic analysis of the regulation of the purified soluble enzyme by protoporphyrin IX, heme and nitrosyl-heme. J Biol Chem 257:13312-13320.

Zabel U, Weeger M, La M, and Schmidt HH (1998) Human soluble guanylate cyclase: functional expression and revised isoenzyme family. Biochem $J$ 335:51-57.

Zhao Y, Schelvis JPM, Babcock GT, and Marletta MA (1998) Identification of histidine 105 in the beta1 subunit of soluble guanylate cyclase as the heme proximal ligand. Biochemistry 37:4502-4509.

Zhuo M, Hu Y, Schultz C, Kandel ER, and Hawkins RD (1994) Role of guanylyl cyclase and cGMP-dependent protein kinases in long-term potentiation. Nature (Lond) 368:635-639.

Zhuo M, Laitinen JT, Li XC, and Hawkins RD (1998) On the respective roles of nitric oxide and carbon monoxide in long-term potentiation in the hippocampus. Learn Mem 5:467-480.

Address correspondence to: Wen-Mei Fu, Pharmacological Institute, College of Medicine, National Taiwan University, 1, Sec. 1, Jen-Ai Road, Taipei, Taiwan. E-mail: wenmei@ccms.ntu.edu.tw 